DOI: 10.2478/rae-2020-0015 Review of Artistic Education no. 192020 121-133

\title{
15. STYLISTIC-INTERPRETATIVE ANALYSIS OF THE CREATION FOR GUITAR SOLO BY HEITOR VILLA LOBOS (Preludes no. 1-4)
}

Daniel Dragomirescu ${ }^{151}$

\begin{abstract}
Along with the structural analysis of the preludes, an interpretive analysis is extremely necessary for a practitioner of this instrument. Carlos Bonell, in an article in the specialized magazine "Guitar" (vol.11 of April 9, published in 1983), states that when the music of Villa-Lobos guitar parts becomes familiar to our ears, it is difficult let us imagine how they were in their "raw" state, in other words, how they were conceived in the composer's imagination. But our duty as performers is to try to give this music its freshness and spontaneity, instead of imitating famous recordings or interpretations, which can only lead us to an outdated and at the same time lacking originality.
\end{abstract}

Key words: creation for guitar, Latin American school, interpretive style for guitar

\section{Stylistic-Interpretative Analysis of Prelude no. 1}

The melody of this prelude represents a contrasting portrait of Brazil and its musical culture, with a melancholic, penetrating and quite sad nature. Together with this sadness, there is also sure optimism, reinforced by a sense of playful movement. The middle section has its origin in the folklore, reminding of the wonderful Brazilian lands, shaped through the capitalization of the guitar lyricism. Prelude no. 1 has a guitar writing, the resources of the instrument being fully exploited, both the polyphonic ones, with the subtilities of the timbre, and the expressive qualities. For the performance of a proper interpretation, we must approach the part without fighting the interpretative concepts of the other guitarists, thus, being able to capitalize more the partition meanings.

Firstly, we must take into account the tempo variations indicated by VillaLobos. The prelude begins with the indication "Andantino expresivo", then, in the median section, it shall transform into "piu mosso". These notes lead us to achieving the contrast between the two sections, thus the first one being sung more settled than the median one, granting the music a serious and at the same time a grandiose nature. The melody, sung on grave strings, entails a continuous vibrato, but allows for an exaggerated rubato or other ostentatious excesses. Eg.1 (m.1-3), H. Villa-Lobos - Prelude No. 1

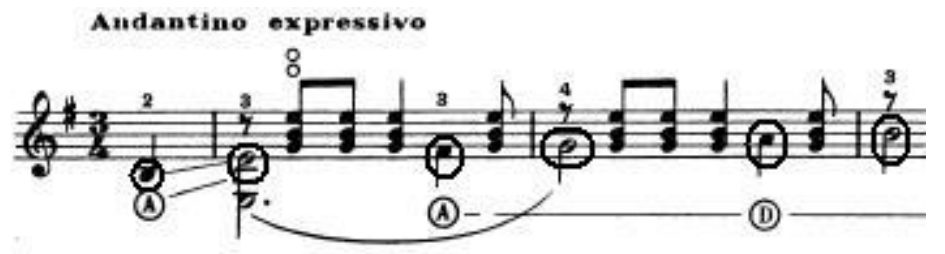

\footnotetext{
${ }^{151}$ Associate Professor PhD., "George Enescu" National University of Arts from Iaşi, Romania, email: dany_guitar2000@yahoo.com
} 
The vibrato technique is achieved identically to bow instruments, mentioning that sounds with along duration cannot be vibrated, due to the decrease over time of the sound amplitude. This technique offers the possibility of leading the melody towards the climax of the musical phrase as well as the fluidity it needs. Since it is about an accompanied melody, the right hand fingering shall resume to using the police (p) for the intonation of the main voice, and i $\mathrm{m}$ and a, for the accompaniment achieved on the other strings. The emphasize of the voice with the soloistic role has its solution in the force of twang of the police, which shall be higher than of the other fingers. This entails the acquisition of a total independence between $\mathrm{p}$ and $\mathrm{i}, \mathrm{m}$, a from the right hand, insisting on the rare study, with the permanent maintenance of the relaxation feeling. The difficulty in the application of this technique emerges in the passages where the melody is sung simultaneously with the accompaniment. Eg.2 (m.6, m.36-38), H. Villa-Lobos - Prelude No. 1

a.

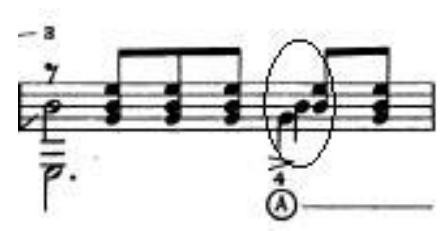

b.

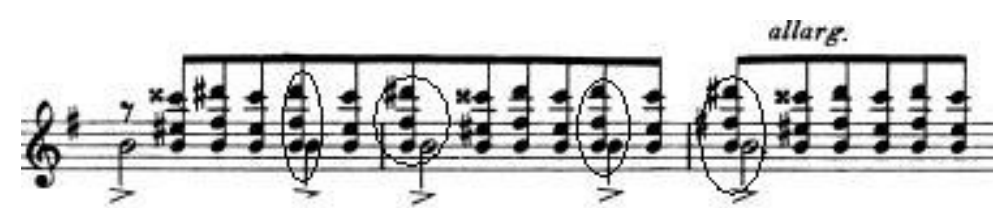

For the fingering used in the first case (a), I recommend the two variants which are as efficient in maintenance of the continuity of the melody as the soloistic part. The first variant consists in the twang of the police of both sounds $\mathrm{g}$ and $\mathrm{b}$ on strings $\mathrm{a}$ and $\mathrm{d}$ respectively, remaining thus $\mathrm{i}$ and $\mathrm{m}$ for the accompaniment notes, respectively $b$ and e free strings. The positive aspect generated by this fingering, is the fact that the index (i) shall be used only for the twang of the notes in the accompaniment and the police shall remain the one leading the melody. The second variant requires the twang with the index of sound $\mathrm{b}$ on string $\mathrm{d}$, the sound belonging to the melody. The approach of this fingering possibility entails an increased attention on the index, modifying its attack force due the passage from an accompaniment sound, to one belonging to the soloistic plan. The settlement of this problem consists in the rare exercise of the fragment, with the permanent focus of attention on the salience of the singer's voice.

The melody on the bass notes and the accompaniment on high strings represent a reminiscence of the cavaquinho (small-sized guitar, originary from Brazil) manner of interpretation or on the mandolin. In the first section, the phrasing must be achieved depending on the formal structure. Due to the fact that each period begins with the same motive, we could create differences in intensity and colour on each of these. Thus, we begin the part in an "mf" and then gradually 
increase from one period to another, up to "forte". This can also be achieved through differences in colour, which consist of the slow movement of the hand towards the tailpiece or the keyboard. But taking into account that this prelude has, however, a folklore influence, the same colour and intensity can be maintained throughout the section.

Another problem with which guitarists confront in the interpretation of this Prelude is represented by the unforeseen sounds produced by the strings, when the fingers slide over them. This ungracious whistle is casued on thick strings and constitutes a delicate moment for any performer. Some, solve the problem by the intentional omission of glissandos and portamentos. But this is toxic both for the music and for the composer's asethetic intentions. Other, somewhat completely different, make these disturbing noises more visible than the music itself. The best solution for their removal is somewhere in the middle, between the two extremes presented, minimising them through technical means. The tricks proper for this situation entail the usage in a certain manner of the fingers of the left hand. Thus, when it is sung with portamento, the finger should be slightly lifted from the string during the movement, and then strongly press even upon the completion of the sliding. It is also possible to use any type of fanned out string or old strings (used) which were slightly smoothed out with the sand paper.

Passing to the median section, John Arran, in article "Technical Hangups", considers to be essential three things, namely: the new key with four sharps, alternance of measures 2/4, 3/4 and the third one, indication "piu mosso". In his opinion, this "piu mosso" represents in itself the key of the section. It is true that some performers sing on a rapid tempo, but at the same time, we must be sure that Villa-Lobos, knowing very well the meanings of indications "allegro" and "vivace" chose, however, "piu mosso". The fingering of the right hand is simple, p-p-p-i-m-a, unfolded on semiquavers with which the first measure in this section begins, after which, the police attacks the first two strings simultaneously. The last note in the measure, B, can be sung by legato with finger 4 . The two sounds $\mathrm{b}$, the free string and on key VII first string, with which the next measure starts, the police twanging both strings can be used.

For note A one shall use finger 2, which, through an ascending legato, sings the $\mathrm{B}$ with finger 4 , and then through a descending one it returns to sound $\mathrm{A}$ for the completion of the ornament. After the police acts again on the first two strings simultaneously in order to continue the sequence, i twangs the next note, E. On the five-sound accord B E A do\# F\# the police is used again for the attack of the five notes (the top note must be removed from the record) and the ornaments at the end of the measure are twanged with i. It is very important to reproduce the rhythm in our mind, as the instrument renders only the ideas we think of. For this, we can work with the metronome set at MM60 and we must try to rhythmically repeat only by clapping our hands, without an instrument, gradually increasing the speed. When the rhythm become easy to reproduce, then the instrument is taken again and it is studied using the same method, the one with the metronome. 
A problem worth mentioning refers to the rhythmic intonation of the ornaments in this section. Often, they are sung as if they were written in the form of triolets. Moreover, in the sequence of accords with barre at the end of the third page (the last measure of 3/8), we must be careful if it is correctly sung from the point of view of sounds. Many students are under the impression of a simple F\# accord, but it is actually a B Major 7 in the second reversal (in 6/4). A correct interpretation requires that the median section be sung in the tempo indicated by the composer, complying with the characteristics of the measure of 3/4.

\section{Stylistic-Interpretative Analysis of Prelude no. 2}

Prelude no. 2 bears three names:

1. "Melodia Capoeira" ("Capoeira Melody"). Capoeira is a dance similar to a fight in the form of ballet, but where nobody is physically touched. Short moments of "ritt - a tempo" (the first one being present in measure 5) have the probable significance of passing final points, as "sword thrusts"152. For achieving the short pause on the top note, not on the preceding note, the latter can be designed as the appoggiatura, "a tempo" being then retaken on the semiquavers on the nonemphasised tempo 3.

2. "Melodia Capadochia" ("Capadochia Melody"). The term of "capadochia" designates a conman, a deceiver.

3. „Homenajen ao Malandro Carioca”. "Homage to a Rio Rascal”. The accord progressions, in close connection to these titles, are typically "chôros" which represent the folk music sung in small street bands. Taking this into account, everything could be interpreted easily and with a sense of humour, without having the part lose its nature.

For the purpose of rendering the effect of the pauses suggested by the composer, these must be interlaced with passages which unfold in tempo and emphasised rubatos, thus preventing the interruptions (fragments) of phrase. We proved that the specimen follows a triple form A - B - A, section B with a strong aspect contrasting with section $A$. Interesting to be seen is the origin of the idea in the median part. This can be observed only if it is sung fluently. Taking a glance on the value of the grave notes in both sections, one can notice that Villa-Lobos develops a simple rhythm, composed of the succession of a half note followed by two quarter notes. Using the same accord pattern for the right hand in various positions, the composer designs section $\mathrm{B}$, which over time, gets a different aspect, but which is categorically built based on the material in the first section. Consequently, it is recommended to emphasize this aspect which imprints coherence and a well-shaped form to the part.

Another problem with which the performer is confronted in the approach of this work emerges in the fragment in section A, measure 14. Thus, the four semiquavers at the beginning of the measure have a relatively simple fingering of

\footnotetext{
${ }^{152}$ John Duarte, The Preludes of Villa-Lobos. Some Notes, part 1, G.I. vol 13, no.1, p.1
} 
the left hand, finger 1 pressing on G\#, simultaneously twanging with the free strings $\mathrm{E}$ gross and D, followed by B and high-pitched $\mathrm{E}$ (both free strings). Next, I recommend the variant that I consider appropriate for the achievement as correct as possible of the passage. For sound D\# on string 1 one shall use finger 4, then it ascendingly slips to E on key XII, with same finger. Now the difficult part is next, namely going down to $\mathrm{E}$, through two triolets in values of thirty-second notes, up to sounds do\# and A from the beginning of the next measure (no. 15). Taking into account indications of "rit" between D and E and then of "a tempo" placed beneath the triolets (in other words, their tempo must reduce the initial pulse of the part), one must not exaggerate by settling too much on the top notes, thus emphasizing the first marking. In order to give the triolets the possibility to sound clearly, we need a fingering that would facilitate this, without using a certain tempo. If we finger these exceptional divisions in the form of accords, only for the study, the moment shall divide into two, losing the movement but also the type of the writing. Eg.3 (m.14, rhythmically modified), H. Villa-Lobos - Prelude No.2

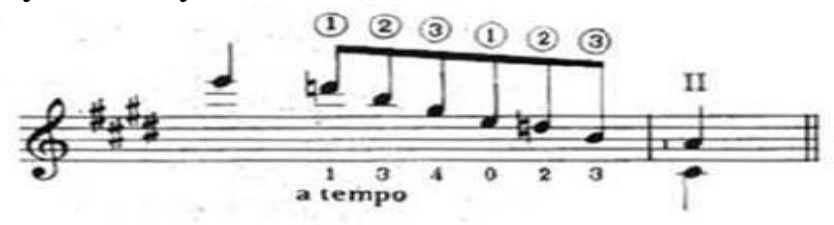

John Arran offers a variant on the fingering that it considers to be satisfactory. In line with it, for natural D on string 1, finger 4 is used, which then, through a descending legato goes down to sound B on the same string, with finger 1. G\# on the second string with finger 3 precedes the free string used for the sound with the same name, E. The following natural $\mathrm{D}$ is available on string 3, on key VII with finger 1, and B is sung on the free string (second string). Using the free string $\mathrm{E}$ offers us the time necessary for changing the position (VII-II) for do\# and A on the second key, from the beginning of the next measure: Eg.4 (m.14, rhythmically modified), H. Villa-Lobos - Prelude No.2

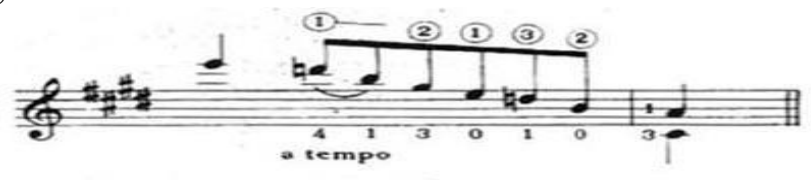

The author considers that "the fingering of the left hand offers a direction to the movement through legato from natural D to B and with the sound of the free string $\mathrm{E}$ before $\mathrm{D}$ on the third string, creates a feeling of harmonious tension which is settled in the next measure" 153 . The personal variant that I consider appropriate for the settlement of this passage is relatively similar to the one previously presented, with the exception of the positioning of sound natural $\mathrm{D}$ which shall use finger 2, on the second string, in space II. This fingering facilitates the easy achievement of the exchange of positions (VII-II) by means of the free string and

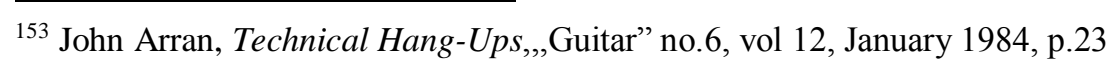


grants colour homogeneity to the sounds composing the melody. Eg.5 (m.14, rhythmically modified), H. Villa-Lobos - Prelude No.2

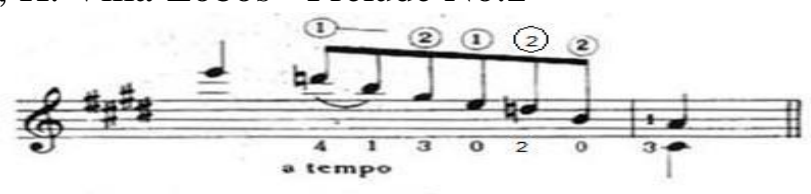

In the median section of this Prelude (p.2,3), the change of the emotional experience is strongly visible, revealing the dramatic aspect of the "malandro". The arpeggios accompanying the melody, sung on grave strings, suggest to the performer the exploitation of subtle rhythmic nuances. As John Duarte shows in his article, Turibio Santos identifies the section with "Rio-Cocknys"154 that he suggests, considering that it must not be treated very deeply from the point of view of musical thinking. And here emerges the problem of the noise caused by the fingers of the left hand through their contact with the grave strings at the moment of movement. But if it cannot be reduced, it does not constitute a tragedy, Villa-Lobos asserting that the performer must get used to considering it part of the music.

The aspect is hard to explain, taking into account the fact that many critics and listeners do not accept these foreign noises as belonging to the musical message. In approaching this part of the Prelude, the left hand plays an important role. Although fixed on only one accord pattern, the changes of positions must be carried out carefully and accurately, without deforming the configuration of the fingers. This is achieved through the individual study of the left hand, using the method of "sober" exchange (without the right hand), gradually going from the rare tempo to a rapid one. Often, students, in the beginning, have the conviction that due to the unique model for the left hand, the interpretation of this stanza is easy to achieve. But it is not so, requiring similarly to the other problems, very much care and effort so that everything shall be well. The fingering of the right hand allows two variants that a performer should know and use in approaching the melody

The first variant consists in using the police only for the notes in the grave register, offering clarity to the contour of the melody and allowing the phrasing of this section to be emphasized. The intercrossing over the finger, regardless of the combination $\mathrm{i}-\mathrm{m}$ or $\mathrm{m}-\mathrm{i}$, has the advantage of the relieving of the second accent in the measure, but at the same time it can be difficult to control if one does not pay enough attention to it. The second fingering variant presents the advantage of an easy creation of an effect of speed and excitation, as the police, moving on all three grave strings, offers a formidable impact to the arpeggio. It is good to know that only when both possibilities are mastered, the guitarist can decide which one fits better to his/her musical taste and the technique stage he/she is in. John Arran, regarding this problem, prefers the first variant as "the agitation of the second one

\footnotetext{
${ }^{154}$ John Duarte, op.cit., part 1, p.1
} 
is already used, being frequently heard" ${ }^{155}$. Indeed, the clarity of the first one allows you to better listen to what Villa-Lobos thought, the noise of the friction on strings being substantially reduced, offering the chance to discover in a natural manner the structure of this work. But for performers with an effervescent temper, the second variant is successfully accepted. Eg.6 (m.35-40) ${ }^{156}$, H. Villa-Lobos - Prelude No.2

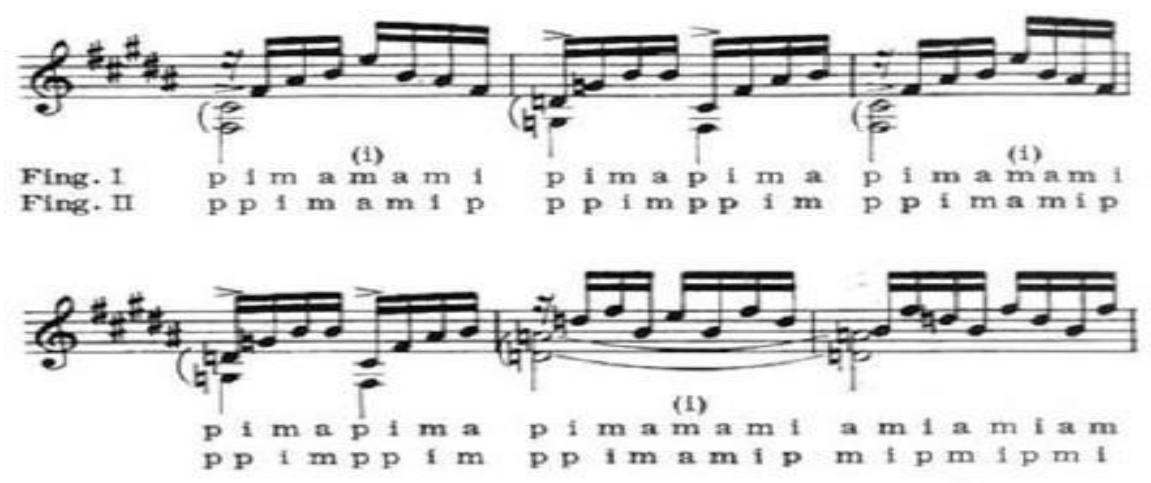

The vigour of the music in Prelude no. 2 derives from the pure simplicity of the means and expressive richness from the compositions for the guitar, revealing the contrast between the calm melody line and the cascade of arpeggios throughout the strings.

\section{Stylistic-Interpretative Analysis of Prelude no. 3}

This prelude, bearing the generic title of "Homage to Bach" contains the proof of the special passion of Villa-Lobos for the music of Johann Sebastian Bach, this being obvious in the phrase in the second section. The balance of the tempos of the two parts represent a decisive element. Some records of certain performers imprint a shockingly rare tempo of stanza B, making the repetition of the sequences lacking imagination, without an attractive perspective. At the same time, it creates the impossibility of maintaining the difference between indications "Andante" for A and "Molto adagio" for B, as indicated by the metronome. "Dolorido", at the end of the second section, represents an indication of manner, of style and, "it is very possible to transmit sadness, without making a reference to a funeral ceremony". ${ }^{157}$

Regarding the balance between the tempos, in this Prelude no. 3, we must take into account that the tempo of "Adagio" is MM.66, provided one equalizes "molto" with the "moltissimo", and the speed of "Andante" is MM.108, thus making the difference between the two, without getting far away from the speeds appropriate to them. This music does not allow exaggerations although the composer generously uses the indications of rallentando and rittenuto, which also contribute to the achievement of balance in the interpretation. John Duarte identifies several problems that must be discussed. One of them refers to the

\footnotetext{
155 John Arran, op.cit., p.23

${ }^{156}$ Ibidem

${ }^{157}$ John Duarte, op.cit., part 1, p.1
} 
semiquavers in the first two measures on the second page (m.20-21), which do not have the indication of being sung by legato, thus, they must, however, be separated, each note being twanged. Binding them means twanging sound D so that next it shall be intonate do through the descending legato, similar to a note with the role of appoggiatura. Similarly, in measure 22 a crescendo is marked, which many guitarists transform into a decrescendo.

Another thing to be mentioned and helps in the achievement of an adequate interpretation is that of not multiplying the markings of dynamics ("rall" in measure 29 and "rit" in measure 35), the markings representing decreases of speed and at the same time, imprinting on the part a static atmosphere. One last problem aims at the repetition of the parts. Thus, if the entire prelude is repeated, as the composer indicated on the score, the descending sequence in section B shall appear four times, being liked by many listeners. The absence of repetition comes against Lobos' indication, but not affecting the balance between the two stanzas. In the interpretation, this remains up to the instrumental performer, both variants being valid. And here we confront we the same noise caused by the friction of fingers on grave strings, but which through a conscious and tenuto study, it can be eliminated. In a great measure, the Preludes are not of a folklore inspiration, but rather improvisational and enthusiastic. "The preludes sound as if they had been composed with the guitar in the lap, with a pencil on the ear and a piece of paper on the table!". ${ }^{158}$

\section{Stylistic-Interpretative Analysis of Prelude no. 4}

The unwanted sounds emerged in the interpretation of Prelude no. 4 can be eliminated by the careful usage of damping (antivibration) techniques. But the removal of the screech emerging during the changing of positions represents another important problem. This noise is caused by the friction of the fingers of the left hand on the strings, especially on the fanned out ones in the bass register. Therefore, I propose for examination a new side of the part. To start with, I suggest the achievement of a record of this work or of another in the finite stage. When the performer is satisfied with the music it renders, I propose for him/her to listen to the recording once again, this time not for the music, but for the noise accidentally emerged. If he/she shall be unpleasantly surprised by their large number, he/she shall insist on removing them from his/her artistic act. However, there are professional guitarists who not having the experience of recordings, are not terrified by the obstruction of these foreign sounds that have become so common in playing the guitar, that they are almost accepted as being part of the music. When we sing, we do not manage to distinguish the noises that are disturbing for the listener. As performers, we normally listen to the music, not to the sounds. However, the listeners surprise them as being distinct from the music, some of them finding them even entertaining. Thus, by recording, one obtains a

\footnotetext{
${ }^{158}$ Carlos Bonell, Masterworks-Carlos Bonell, „Guitar”, vol.11, nr.9, apr.1983, p.10
} 
different perspective of the interpretative act, achieving a first step in their elimination, being first and foremost aware of their existence.

Finally, the part must be registered once again, taking into account the avoidance of noises. If these were eliminated, one shall notice how clear the music rendered has become, at the same time perfecting the technique for the interpretation on the guitar. In this context, I wish to deepen the artistic side of Prelude no. 4 from the perspective of this point of view. The part begins with the twanging of the first note E, in the XIV space on the fourth string, D. Using this fingering, we grant the sound a sonority and a special force, but at the same time there is also the problem of the removal of the "swoosh" caused throughout the movement to the next note, B, placed on the same string. A simple solution would be the one suggested by Villa-Lobos, namely, choosing another new fingering. Thus, note E can be intoned on the third string, G, as it is indicated in the score. A manner of avoiding the noise caused by the friction of the fingers of the left hand on the thick strings during the changes of position constitutes the re-finger of the notes on these strings (especially the fourth) so that these shall be placed on the thin ones (without matting). Sometimes, the approach of another finger completely changes the succession of positions, which requires an additional study for the settlement of difficult passages. But, as long as the re-finger manages to eliminate the problem in itself of the disturbing sounds, is worth all the effort. Although a new variant of finger must be chosen carefully, this is not always possible. In the case of the first notes of Prelude no. 4 their re-finger is not necessarily needed. I consider it necessary to mention that when the choice established destroys the musical colour or idea desired, it is good to search for another solution for the purpose of solving the problem of noises. Between notes $\mathrm{E}$ and $\mathrm{B}$ I consider it fit the design of a portamento (a subtle slipping into the vocal manner). No other technique causes a better legato (singing without an obvious pause) or a more expressive connection between those sounds. For the carrying out of this technique without a prior friction on the strings, it is necessary to twist the fingertips of the left hand so that the appropriate strings shall be touched by the part with the soft leather of the last phalanges. By positioning the hand in this manner, the execution on the guitar of certain more beautiful and more expressive sounds is made possible. First of all, I recommend the attempt of several sliding and changes in order to chef whether such a technique is successful or not.

Some guitarists who have a thicker texture of the fingertips and thus have clavus, these can be soften in hot water, drying and then smoothing them with a thin glass paper. Another solution is represented by the massage with cream or oil inside the clavus. At the same time, it is impetuously necessary the correction of the technique of the left hand if the hard skin of the fingertips is too damaged. If one uses a guitar whose response to attack is good, the pressing force in order to maintain a sound is very little, sometimes only the weight of the finger itself being sufficient. Generally, renowned guitarists have soft fingertips (with or without clavus), as they press the strings correctly, requiring a pressing force sufficient 
only to make the notes vibrate. Usually, the clavus is caused by the exaggerated force with which it is pressed on the keys. If there are such problems, it is recommended to never bend the last articulation of the thumb of the left hand, it being placed in the middle of the back of the neck.

Exercising for five or ten minutes with a great focus only on the behaviour of the finger, we shall discover that its position, throughout the work, it is not always the correct one. Thus, when the modification of another wrong fingerings of the left hand is wanted, the correction of all passages where the thumb is bent is also recommended. If there are difficulties (fatigue, problems with the changes, too much effort when pressing), I suggest the study without this finger touching the back of the neck regardless of the complexity of the position that must be sung. It is necessary that the passage is learned very well (even memorised) so that later on one shall bring back the thumb in the correct position. The usage of the study methods previously presented have as a final purpose of the regulation of the manner of action of the thumb in question which is similar to a guide for the entire hand and not as a thumb screw which through a strong pressure "chokes the neck". These techniques grant the maximum effective power when they are exercised in short reprises of five up to ten minutes, carried out along certain longer periods of time. And one more thing: one must not make any compromise in the identification and remedy of mistakes.

By bending the phalanges of the fingers in the left hand and sliding with the soft part of the fingertips, one shall remove any sound that could alter the musical idea. And if the fingertips are too rough or have clavus, the execution of a noise of the portamento on the fanned out strings is impossible to achieve. If the phalanges are thin, the technique of their bending shall not function in rough conditions of singing such as rainy weather or in low temperatures. Regarding the method of changes, these are based on the lifting of the finger at the moment of their movement on the strings. Another problem with which the instrument is confronted in the approach of this work is constituted by the stopping of the strings, so necessary for the purpose of obtaining the accuracy of the interpretation during the artistic action. Based on this idea, the first note of the prelude (E), if it is twanged using a correct manner of attack (apoyando), shall give rise to harmonics. For some guitars, the variety of harmonics shall amplify the sound of the note and in this case, this could be let to vibrate as long as possible. But generally, the entire sonorous material must be very clearly intoned.

Thus, I shall explain how it is possible to stop all the strings, with the exception of the one on which a sound is intoned. A first method consists in using the index finger from the left hand which, if not engaged in another activity, could be set transversally on the keyboard as if executing a barre, carrying out a light pressure necessary only to stop those strings continuing to vibrate. The damping of the sounds can also be done with the fingers in the right hand in the following manner: i (indication or index), m (average or medius), a (ringlike) on highpitched strings and $\mathrm{p}$ (police or thumbprint) on grave strings (on the basses). As 
the melody of this part must be song very intensely, I shall begin to twang with the police on the fourth string (D) and not as it is written down in the score, on the third string $(\mathrm{G})$. First of all, I dim the three head strings by placing fingers $\mathrm{i}, \mathrm{m}$ and a, maintaining them in a fixed position throughout the measure. Immediately after the first sound, I shall dim strings low A and $\mathrm{E}$ by introducing the police between them, the pulpy fingertip stopping the fifth, and the left side the sixth. The next note, $\mathrm{B}$, shall be intoned on the same string, and the identical usage of the $p$ prepares the twanging of the third one, G, placed on the fifth string. At the moment of attacking $\mathrm{G}$, the finger on the left hand lifts from $\mathrm{B}$, next being its stopping. Simultaneously, it bends so that it can touch the fourth string, aspect which offers the freedom to lift the finger that we used for the previous sound. Immediately after we have sung note G, I dim the sixth string with the police and do the same thing with the fourth note, F\#. In this case, the technique of tipping the finger of the left hand so that it stops vibrating the fourth string.

At the same time with the attack of the fifth sound, D, fingers i, $m$ and a move with a string lower each, thus dimming the fourth, the third and respectively, the second one. At the moment, I do nothing yo stop string low E, as D must be twanged rapidly, but after the next E sound is sung, I shall stop it with the p. While E vibrates on the fifth string, a discrete tin whistle emerges on the fourth one, tin whistle which beautifies the sonorous atmosphere. For the first note in measure no. 3, also E, new dimming problems emerge. Here, stopping the head strings is executed with $\mathrm{i}, \mathrm{m}$ and a simultaneously with the twanging of the abovementioned sound, on the fourth string. As for the rest, throughout the section, I dim using the methods previously described. In the next section, the one with arpeggios (m. 11-26), we must emphasize the melody present in the bass plan. It is twanged with the p, and for the three notes accompanying it one shall use $\mathrm{i}, \mathrm{m}$ and a, thus balancing the sonority of each arpeggio accord without altering the emphasize on the melody. Fingers i, $m$ and a have a soft attack, being ready for a future arpeggio by placing them on acute strings, simultaneously with the twanging of the sound on the grave register. This increases the emphasize of the melodic plan by dimming those strings, similar to the pedal technique used by pianists in similar passages. Together with twanging the note superior do at the end of measure 25, I stop the string using a twang in apoyando. At the same time, I place the police on the same string, preparing it for stopping the last sound $(\mathrm{G})$ of the measure. All the strings are dimmed by placing the $\mathrm{p}$ on top of them, except the first one. When the B octave is attacked of measure no. 26, the dimming of the four strings is maintained.

The subsequent section (measures 27-32) contain notes in the form of harmonics. Throughout this part, the melody should be interpreted on only one line. Thus, the melodic material in measure 27 shall be sung, then the attack on the first sound in measure 28 (E), located on the first string, shall be stopped. There is the possibility to hear other several notes, especially D tin whistle on the third string. If Villa-Lobos would want such an effect, he should not have tied 
inside the next measure those sounds intended to vibrate, as he did with the harmonics in the bass plan (the Es with the tailets downward in measure 28) or indicate legatos as the ones present in measure no. 25. But the first note in measure 28 , being part of the melody, must vibrate alone, due to which Villa-Lobos emphasized this desire by marking a pause placed underneath. For clarity, the last four strings are stopped with the $\mathrm{p}$, and by using the twang style of apoyando, the second string is also dimmed.

After the intonation of the second sound in measure 27, it is necessary to stop string B. If the sonority generated by other strings is obvious, it must be stopped so that the melody shall sound purely. For the entire measure the dimming of basses shall be carried out with the p. The dimming of the first string shall be done with the $\mathrm{m}$ and immediately the second note in the measure shall be sung with finger i. Moreover, I could stop the high-pitched E string simultaneously with the twang of the second sound, but it could be heard better by stopping only afterwards. In this context, I recommend trying both variants and using the one better fitting the musical taste of the interpreter. One shall continue using the same dimming technique for the third note of the same measure as well, note located on string G. For stopping it, the next sound (F\# tin whistle) shall be twanged in apoyando. Immediately after the last harmonics, the second string is also dimmed with finger i. For the moment, instead of suppressing the sonority of the first tin whistles with the right hand, one could use the left one, simultaneously stopping the adjacent string by using the same finger with which it was previously attacked. Obtaining this clear approach of the melody entails the usage of all techniques entailing the execution of this. Practically, the entire part could bear the print of a proper interpretation using the methods described above. One can notice the fact that I have been concerned basically by the sound of each note about which we have discussed.

\section{Conclusions}

If any guitarist shall take into account these details and shall apply them, he/she shall certainly develop the level of interpretation of the entire repertoire. Since in the last decades the sound of the guitar has become a landmark of culture of Latino-American countries, we are motivated to concern ourselves with the promotion of a repertoire which shall include various musical works written by Latino-American composers born between the $19^{\text {th }}$ century and the middle of the $20^{\text {th }}$ century. In this age, important composers and interpreters of this geographical areas have distinguished themselves, and their contributions led to the extension of the technique and development of the language within the repertoire for classical guitar.

\section{References}

1. Arran, Johnn, Technical Hang-Ups,,Guitar” no.6, vol 12, January 1984, no.1

2. Bonell, Carlos, ,Guitar” (vol.11 din 9 aprilie, apărută în 1983), no.1 
3. Cubierta, Radames Giro, Gamboa, Rusky, 1982, Leo Brouwer, La Musica, Lo Cubano y la Innovacion, Editorial Letras Cubanas, Calle G. num.505, El Vedado, Ciudad de la Habana, Cuba, Sobre el autor

4. Danner, Peter, spring 1992, The Guitar in Latin-America. A personal view by Carlos Barbosa-Lima as told to Peter Danner, part 1, GFA Soundboard (XIX/1)

5. Dumond, Arnaud et Denis, Francoise Emmanuelle, 1988, Entretiens avec Leo Brouwer, Les Cahiers de La Guitare, trimestrul 4, Premiere rencontre, avec Arnaud Dumon

6. Duarte, John, The Preludes of Villa-Lobos. Some Notes, part 1, G.I. vol 13, no.1 7. Golea, Antoine, 1987, Muzica din noaptea timpurilor până în zorile noi, vol II, Editura Muzicală, Bucureşti

8. Ștefănescu, Ioana, 2002, O istorie a muzicii universale, Vol. IV, Editura Muzicală, București

9. Santos, Turibio, 1985, Heitor Villa Lobos and the guitar, originally published by the Museu Villa-Lobos, 1975, first published in English by Wise Owl Music, Gurtnacloona, Bantry, Co.Cork, Ireland

10. Tanenbaum, David, 1992, The essential Studies, study notes, insights and commentary on Leo Brouwer's 20 Estudios Sencillos, Guitar Solo Publications (GSP 28), San Francisco, 1992, Introduction

11. xxx 2006, Dicţionar de mari muzicieni, Editura Univers enciclopedic, Bucureşti

12.xxx 1990, Enciclopedia Marilor Maeştrii ai Muzicii, vol.V, Le Livre de Paris - Hachette,

13. en.wikipedia.org/wiki/Musician_Wren 